\title{
Optimal tax Deductions for Net Losses Under Private Insurance With an Upper limit
}

\author{
Rachel J. Huang \\ Larry Y. Tzeng
}

\begin{abstract}
Kaplow (1992b) shows that governments should not provide a tax deduction for net losses when a private insurance contract is available. However, his findings rest on the assumption that the private insurance is proportional coverage. We find that Kaplow's conclusions may not hold when the private insurance contract contains an upper limit. The findings of our article show that Kaplow's conclusions are sensitive to the assumption that the insurance contract is available in the private market.
\end{abstract}

\section{INTRODUCTION}

The federal government of the United States allows individuals to deduct some of their losses from their taxable income. ${ }^{1}$ However, Kaplow (1991b, 1992b) proves that, when private insurance is available, tax deductions for net losses are inefficient. He shows that a tax deduction for net losses plays a similar role to a social insurance and reduces an individual's demand for private insurance. He also proves that a tax system without deductions for net losses Pareto dominates a tax system with deductions for net losses. In addition, he indicates that his finding is robust after taking moral hazard and administration costs into consideration. ${ }^{2}$

This article modifies Kaplow's (1992b) findings to explain why tax deductions for net losses might be socially optimal. In Kaplow (1992b), the private insurance is exogenously assumed to be proportional to coverage. However, in reality, the private

Rachel J. Huang is an Assistant Professor in the Finance Department, Ming Chuan University, Taipei 111, Taiwan. Larry Y. Tzeng is working in Department of Finance, National Taiwan University, Taipei, 106, Taiwan. The authors can be contacted via e-mail: rachel@mcu.edu.tw and tzeng@ntu.edu.tw. Huang would like to thank the National Science Council in Taiwan for financial support (Project number 94-2416-H-130-015).

${ }^{1}$ The amount of tax returned for itemized casualty and theft loss deductions was about $\$ 1.6$ billion in 2003, and that for medical and dental expenses deductions was $\$ 55$ billion with a growth rate of 6 percent. Unlike the casualty and theft losses, the medical expenses include insurance premiums.

2 When the private insurance market suffers from an adverse selection problem, the government may deal with the market failure by providing a simple lump-sum taxes and subsidies system (Crocker and Snow, 1985) or a linear premium subsidy (Selden, 1999). 
market contains many other commonly used forms of insurance contract, such as a policy with an upper limit. Therefore, we reexamine whether Kaplow's (1992b) findings still hold when the form of the optimal private insurance is a contract with an upper limit. ${ }^{3}$

The literature has documented that the optimal private insurance contains an upper limit on coverage for the following reasons: price regulation (Raviv, 1979), the insured's option of bankruptcy (Huberman, Mayers, and Smith, 1983), the insured's option for converting or trading the damaged properties (Garratt and Marshall, 1996), or the manipulation of audit cost (Picard, 2000).

We first study whether a tax deduction for net losses is optimal, where the private insurance market is that characterized by Raviv (1979) in which the optimal private insurance is endogenously determined to be a policy limit contract due to price regulation. We further show that the assumption of price regulation is not necessary for our main conclusion. We exogenously assume that the private insurance is a contract with an upper limit and reexamine whether the policy limit alone (without price regulation) makes tax deduction for net losses socially optimal.

The findings of our article show that Kaplow's (1992b) conclusions are sensitive to the assumptions regarding the form of the insurance contract in the private market. We show that, if the private insurance is a policy with an upper limit, then the government may have an incentive to provide a tax deduction for net losses to individuals.

In the section on "Optimal Tax Deductions for Net Losses," we examine the optimal tax deduction under private insurance with a policy limit. Our conclusions and applications are presented in the final section.

\section{Opmanal Tax Deductions for Net Losses}

The optimal tax deduction is determined by a two-stage process. In the first stage, the government decides the tax deduction rate. In the second stage, given the tax deduction, the insured and the insurer choose the optimal form of the insurance contract in the private market. We solve the optimal tax deduction rate by means of a backward induction. Specifically, we evaluate whether the optimal tax deduction for net losses is zero.

Assume that a representative risk averse insured with initial wealth $w$ faces a random loss $x$ with a cumulative density function $F(x)$ for $0 \leq x \leq L$, where $L$ is the maximum of the loss. The insured is willing to pay premium $P$ to obtain an insurance contract with indemnity $I(x), 0 \leq I(x) \leq x$, if loss $x$ occurs. Following Kaplow (1992b), we

\footnotetext{
${ }^{3}$ Proportional coverage, deductibles, and policy limits are the most commonly used contracts in the private insurance market. It is obvious that Kaplow's (1992b) findings hold if the optimal private insurance contract is proportional to coverage, as Kaplow assumed. It can be also shown that Kaplow's findings hold if the optimal private insurance is a deductible contract. Thus, our article focuses on the case where the optimal private insurance contains a policy limit.

4 It is worth noting that a government establishes price regulation for several reasons (Rejda, 1998). For example, it is desired to compensate for inadequate consumer knowledge, to ensure that insurance is available, to avoid insurer insolvency, or to maintain reasonable rates.
} 
assume that the individual has a tax deduction proportional to net losses, $t(x-I(x))$, where $t \in[0,1]$ denotes the tax deduction rate. Like Kaplow, we also assume that the government finances the tax deduction system through a lump sum tax $\tau$. Assume that the insured is an expected utility maximizer, and that his/ her utility function $U($. is twice differentiable, increasing, and concave downward. Thus, the expected utility of the insured is

$$
E U=\int_{0}^{L} U(w-P-(x-I(x))(1-t)-\tau) d F(x)
$$

where $E$ denotes the expectation operator.

We assume that the insurance market is competitive, and the insurance companies are risk neutral. However, risk-neutral insurers might act as if they were risk averse. Stiglitz $(1989,2002)$ and Greenwald and Stiglitz (1990) have documented that both bankruptcy costs and agency costs are two candidates that drive a risk-neutral firm acting in a risk-averse manner. For example, an increase in risk could increase the bankruptcy cost and result in underinvestment for a new project when external financing is costly (Smith and Stulz, 1985; Froot, Scharfstein, and Stein, 1993; Tufano, 1996; Doherty, 2000). In other words, a risk-neutral firm would give up a positive net present value (NPV) project while the bankruptcy costs are increasing with risk, which means that the firm's value function is not equal to the discounted present value of profit. Instead, the value function is concave as Greenwald and Stiglitz (1990) indicates. Thus, similar to Doherty and Smetters (2005), we use a concave function $V($.$) to approximate the value function of an insurer.$

Moreover, we implement price regulation as in Raviv (1979). The regulated price is

$$
P=R(E(I(x)))
$$

where $R$ is a function of expected indemnity. For the sake of simplicity, we assume that $R$ equals $(1+\lambda+\delta) E(I(x))$, where $\lambda \geq 0$ is an expense loading for insurance and $\delta \geq 0$ denotes a loading to compensate for the risk-averse attitude of insurers. Without a positive $\delta$, a risk-averse insurer with initial wealth $s$ will not provide insurance.

Thus, the insurer will offer an insurance contract, which is determined by

$$
\begin{aligned}
\underset{P, I(x)}{\operatorname{Max}} E V & =\int_{0}^{L} V(s+P-(1+\lambda) I(x)) d F(x) \\
\text { s.t. } P & =(1+\lambda+\delta) E(I(x)) .
\end{aligned}
$$

Raviv (1979) demonstrated that a risk-averse insurer facing Equation (3) will determine a policy with an upper limit. The insurance company provides the insured with full coverage when the amount of the loss does not reach the amount of the limit.

\footnotetext{
${ }^{5}$ As mentioned in Raviv (1979), price regulation is frequently enforced in the insurance market and the insurer therefore operates subject to a regulatory constraint on premiums.
} 
Once the loss exceeds the limit, a fixed reimbursement is paid. The optimal indemnity can then be written as

$$
\begin{aligned}
& I(x)=x, \text { if } \quad x \leq \bar{x} \\
& I(x)=\bar{x}, \text { if } \quad x>\bar{x}
\end{aligned}
$$

where $\bar{x}$ denotes the policy limit. Raviv (1979) argued that $\bar{x}$ varies with the function $R$. In other words, the insurer will determine an optimal level of the policy limit according to the regulation formula but without taking the insured's utility into account. Therefore, the insured has no power to determine the level of the upper limit.

Next, we demonstrate that a nonzero tax deduction rate is optimal when the optimal private insurance consists of a contract with an upper limit as shown in Equation (4). Kaplow (1992b) showed that the government could have an incentive to provide a tax deduction for net losses if it is more efficient than the private insurer in terms of administration costs. To control for the effect of these costs, we assume that the government's loading is equal to the insurer's loading $\lambda+\delta$. Therefore, given that the optimal private insurance contract is a policy with an upper limit, the budget constraint used to finance the tax deduction system is then

$$
\tau=(1+\lambda+\delta) \int_{\bar{x}}^{L}(x-\bar{x}) t d F(x) .
$$

Thus, the government chooses an optimal tax deduction rate to maximize the weighted average of the insured's expected utility and the insurer's expected value function subject to Equation (5). The model can be written as

$$
\begin{array}{rl}
\operatorname{Max}_{t} & E U+\theta E V \\
= & \int_{0}^{x} U(w-P-\tau) d F(x)+\int_{x}^{L} U(w-P-(x-\bar{x})(1-t)-\tau) d F(x) \\
& +\theta\left\{\int_{0}^{x} V(s+P-(1+\lambda) x) d F(x)+\int_{\bar{x}}^{L} V(s+P-(1+\lambda) \bar{x}) d F(x)\right\} \\
\text { s.t. } \tau=(1+\lambda+\delta) \int_{x}^{L}(x-\bar{x}) t d F(x)
\end{array}
$$

where $\theta$ is a nonnegative constant.

The above model differs from Kaplow's (1992b) in one essential way. According to Kaplow, the tax deduction rate influences the insured's private insurance decision. In Kaplow, the optimal insurance amount is determined by maximizing individual's expected utility, which is a function of tax deduction rate. On the other hand, the optimal insurance contract in our model is derived by maximizing insurer's expected value function subject to price constraint. Notice that in Equation (3), the tax deduction rate plays no role in either the insurer's value function or the regulated price function. Therefore, the tax deduction rate has no impact at all on the level of the upper limit. 
Since the insurer's value cannot be affected by the tax deduction rate, we can treat the insurer's expected value function $E V$ as a constant with respect to $t$. Thus, the government's objective function (6) can be rewritten as follows:

$$
\begin{aligned}
\operatorname{Max}_{t} E U & =\int_{0}^{\bar{x}} U(w-P-\tau) d F(x)+\int_{\bar{x}}^{L} U(w-P-(x-\bar{x})(1-t)-\tau) d F(x) \\
\text { s.t. } \tau & =(1+\lambda+\delta) \int_{x}^{L}(x-\bar{x}) t d F(x) .
\end{aligned}
$$

The first-order condition of Equation (7) is

$$
\begin{aligned}
\frac{d E U}{d t}= & \int_{0}^{\bar{x}}\left(-\frac{d \tau}{d t}\right) U^{\prime}(w-P-\tau) d F(x) \\
& +\int_{x}^{L}\left(x-\bar{x}-\frac{d \tau}{d t}\right) U^{\prime}(w-(x-\bar{x})(1-t)-P-\tau) d F(x),
\end{aligned}
$$

where,

$$
\frac{d \tau}{d t}=(1+\lambda+\delta) \int_{\bar{x}}^{L}(x-\bar{x}) d F(x)>0
$$

Therefore, we derive the following proposition.

Proposition 1: When a private insurance contract contains an upper limit due to price regulation, the optimal tax deduction rate $t \in(0,1)$ if

$$
\begin{aligned}
&(1+\lambda+\delta) \int_{\bar{x}}^{L}(x-\bar{x}) d F(x)\left(\int_{0}^{\bar{x}} U^{\prime}(w-P) d F(x)+\int_{\bar{x}}^{L} U^{\prime}(w-x+\bar{x}-P) d F(x)\right) \\
&<\int_{\bar{x}}^{L}(x-\bar{x}) U^{\prime}(w-x+\bar{x}-P) d F(x) .
\end{aligned}
$$

Proof: The proof is constructed by two parts. First part of the proof establishes the condition for the optimality of a positive tax deduction, $t>0$. The second part establishes the conditions for $t<1$.

Evaluating Equation (8) at $t=0$, we find

$$
\begin{aligned}
\left.\frac{d E U}{d t}\right|_{t=0}= & \int_{0}^{\bar{x}}\left(-\frac{d \tau}{d t}\right) U^{\prime}(w-P) d F(x) \\
& +\int_{\bar{x}}^{L}\left(x-\bar{x}-\frac{d \tau}{d t}\right) U^{\prime}(w-x+\bar{x}-P) d F(x)
\end{aligned}
$$


If Equation (11) is positive, that is,

$$
\int_{0}^{\bar{x}}\left(-\frac{d \tau}{d t}\right) U^{\prime}(w-P) d F(x)+\int_{\bar{x}}^{L}\left(x-\bar{x}-\frac{d \tau}{d t}\right) U^{\prime}(w-x+\bar{x}-P) d F(x)>0
$$

then a zero tax deduction rate will be dominated by a nonzero tax deduction rate. By substituting Equation (9) into Equation (12), we can obtain Equation (10).

Since the tax deduction rate does not affect the level of the policy's upper limit, Equation (7) implies that the insured purchases co-insurance from the government. Based on Arrow (1963) and Mossin (1968), we conclude that the co-insurance rate (tax deduction rate) is less than one when the insurance provider (the government) has a positive cost loading.

Proposition 1 complements Kaplow's (1992b) finding. When the optimal private insurance is a contract with an upper limit due to price regulation, as suggested by Raviv (1979), the government should set up a nonzero tax deduction rate if Equation (10) holds.

Equation (10) indicates that the government should set up a nonzero tax deduction rate when the insured's marginal benefit is greater than the insured's marginal cost. When facing a tax deduction system, the insured's final wealth will increase due to the decrease in after-tax net losses. This effect will inflate the insured's utility level by $\int_{z}^{L}(x-\bar{x}) U^{\prime}(w-x+\bar{x}-P) d F(x)$, which is the right-hand side of Equation (10), and which may also be viewed as the insured's marginal benefit of establishing a tax deduction system. On the other hand, the insured's final wealth will decrease through the increase in the tax payment. The insured's utility level will be reduced by $\frac{d \tau}{d t}\left(\int_{0}^{z} U^{\prime}(w-P) d F(x)+\int_{x}^{L} U^{\prime}(w-x+\bar{x}-P) d F(x)\right)$, which is the left-hand side of Equation (10), and may be regarded as the insured's marginal cost of providing a tax deduction system. It is very important to recognize that, to satisfy Equation (10) and make the tax deduction for net losses socially optimal, the government's loading $\lambda+$ $\delta$ cannot be too large. ${ }^{6}$

The mechanism that makes our conclusion differ from that of Kaplow (1992b) is that the private insurance market is incomplete. Since in the private insurance market the insured is compensated by only a fixed amount above the policy limit, this leaves room for the government to enhance the social welfare by providing extra reimbursement for the insured. To manage the uncovered risk above the policy limit, the insured would be better off transferring the uncovered risk to an indemnity provider, which is the government in Equation (7). Thus, if the government provides a tax deduction for net losses, for all losses above the policy limit the insured will not only obtain a fixed reimbursement from the insurer, but will also receive social insurance (a tax deduction) from the government. Since the insured can pay a lump-sum tax to exchange a tax deduction for uncovered losses above the policy limit, the insured is better off.

\footnotetext{
${ }^{6}$ We do not ask that the government be more efficient than the insurer since the government's loading and the regulated insurance loading are assumed to be the same.
} 
It should be pointed out that only the existence of a policy limit can make the tax deduction for net losses socially optimal. In Equation (7), we use price regulation to justify the optimal private insurance being a contract with an upper limit. Indeed, there are several other rationales that could generate an optimal insurance contract with an upper limit as discussed in the "Introduction." In the Appendix, we show that the assumption of price regulation is not necessary for our results. We reexamine our conclusions by exogenously assuming that the private insurance is a contract with a policy limit and that the insurance is priced in a competitive market. We find that our main conclusion still holds after we relax the assumption of price regulation.

\section{Concuusions and Appucations}

Kaplow (1992b) argues that tax deductions for net losses are inefficient if the available insurance in the private market is based on proportional coverage. In complementing his findings, we demonstrate that a tax system with deductions for net losses may Pareto dominate a system with zero tax deductions if the optimal insurance in the private market consists of a contract with an upper limit. In conclusion, Kaplow's findings are sensitive to the assumption of an insurance contract in the private market. When private insurance provides incomplete insurance, the government has an opportunity to improve the social welfare by providing tax deductions.

Our findings could be extended directly to focus on issues related to government reliefs. Kaplow (1991a, 1992a) indicates that if the private insurance contract is affected by the government's action, it is not socially optimal for a government to provide relief. However, we could modify our model by setting up a fixed amount of relief rather than a proportional tax deduction for net losses and show that a positive amount of relief would increase social welfare.

On the other hand, a tax deduction for net losses has nearly the same function as public insurance. The former reimburses the insured through an income tax system, whereas the latter covers the insured's losses directly. In the literature, researchers have engaged in many insightful debates on whether the government should provide public insurance when private insurance is available (e.g., see Besley, 1989; Selden, 1993; Petretto, 1999). Although they have dissenting views, they all exogenously assume that the private insurance market provides proportional coverage. Further research that adopts an endogenous optimal private insurance contract could generate fruitful findings on the topic of public insurance versus private insurance.

\section{Appendix}

In this appendix, we will show that a zero tax deduction rate is dominated if the optimal private insurance contract exogenously exhibits the form with an upper limit as in Equation (4).

Again, we solve the optimal tax deduction by means of a backward induction. First, the private insurance market will decide the level of the coverage limit given the information regarding $t$ and $\tau$. Assume that the insurer is risk neutral and let $\lambda$ denote the expense loading of the insurer. Thus, given a tax deduction system, the optimal upper limit is determined by maximizing the insured's expected utility subject to the insurer's participating constraint: 


$$
\begin{aligned}
\operatorname{Max}_{x} E U & =\int_{0}^{x} U(w-P-\tau) d F(x)+\int_{\bar{x}}^{L} U(w-P-(x-\bar{x})(1-t)-\tau) d F(x) \\
\text { s.t. } P & =(1+\lambda)\left[\int_{0}^{\bar{x}} x d F(x)+\int_{\bar{x}}^{L} \bar{x} d F(x)\right]
\end{aligned}
$$

The first-order condition for an internal solution will be

$$
\begin{aligned}
\Gamma= & -\int_{0}^{x} \frac{d P}{d \bar{x}} U^{\prime}(w-P-\tau) d F(x) \\
& +\int_{x}^{L}\left(-\frac{d P}{d \bar{x}}+1-t\right) U^{\prime}(w-P-(x-\bar{x})(1-t)-\tau) d F(x)=0,
\end{aligned}
$$

where,

$$
\frac{d P}{d \bar{x}}=(1+\lambda) \int_{\bar{x}}^{L} d F(x)>0
$$

We further assume that the government loading is the same as the insurance loading. Thus, given Equation (A2), the government will choose an optimal tax deduction rate to maximize the insured's expected utility under the government's budget constraint:

$$
\begin{aligned}
\underset{t}{\operatorname{Max}} E U & =\int_{0}^{\bar{x}} U(w-P(\bar{x})-\tau) d F(x)+\int_{\bar{x}}^{L} U(w-P(\bar{x})-(x-\bar{x})(1-t)-\tau) d F(x) \\
\text { s.t. } \tau & =(1+\lambda) \int_{x}^{L} t(x-\bar{x}) d F(x) .
\end{aligned}
$$

The first-order condition of the above maximization problem will be

$$
\begin{aligned}
\Lambda= & -\int_{0}^{\bar{x}} \frac{d \tau}{d t} U^{\prime}(w-P(\bar{x})-\tau) d F(x) \\
& +\int_{\bar{x}}^{L}\left(x-\bar{x}-\frac{d \tau}{d t}\right) U^{\prime}(w-P(\bar{x})-(x-\bar{x})(1-t)-\tau) d F(x)
\end{aligned}
$$

where,

$$
\frac{d \tau}{d t}=(1+\lambda) \int_{x}^{L}\left(x-\bar{x}-t \frac{d \bar{x}}{d t}\right) d F(x)
$$

To demonstrate that a nonzero tax deduction rate is optimal, we now prove that Equation (A5) evaluated at $t=0$ is positive. To prove that $\left.\Lambda\right|_{t=0}$ is positive is equivalent to proving that 


$$
\left.\Lambda\right|_{t=0} \times\left.\frac{d P}{d \bar{x}}\right|_{t=0}-\left.\Gamma\right|_{t=0} \times\left.\frac{d \tau}{d t}\right|_{t=0}>0
$$

since $\left.\frac{d P}{d x}\right|_{t=0}>0$ and $\left.\Gamma\right|_{t=0}=0$

Define $\Psi=\int_{\bar{x}(0)}^{L}(x-\bar{x}(0)) d F(x)$, where $\bar{x}(0)$ is the optimal policy limit when $t=0$. Thus,

$$
\begin{aligned}
& \left.\Lambda\right|_{t=0} \times\left.\frac{d P}{d \bar{x}}\right|_{t=0}-\left.\Gamma\right|_{t=0} \times\left.\frac{d \tau}{d t}\right|_{t=0} \\
& \quad=(1+\lambda) \int_{x(0)}^{L}\left((x-\bar{x}(0)) \int_{x(0)}^{L} d F(x)-\Psi\right) U^{\prime}(w-P(\bar{x}(0))-(x-\bar{x}(0))) d F(x) .
\end{aligned}
$$

Notice that, for all $x$ such that $(x-\bar{x}(0)) \int_{x(0)}^{L} d F(x) \leq \Psi$, we have

$$
U^{\prime}(w-P(\bar{x}(0))-(x-\bar{x}(0))) \leq U^{\prime}\left(w-P(\bar{x}(0))-\frac{\Psi}{\int_{x(0)}^{L} d F(x)}\right)
$$

For all $x$ such that $(x-\bar{x}(0)) \int_{x(0)}^{L} d F(x)>\Psi$, we have

$$
U^{\prime}(w-P(\bar{x}(0))-(x-\bar{x}(0)))>U^{\prime}\left(w-P(\bar{x}(0))-\frac{\Psi}{\int_{x(0)}^{L} d F(x)}\right)
$$

Thus,

$$
\begin{aligned}
& (1+\lambda) \int_{\bar{x}(0)}^{L}\left((x-\bar{x}(0)) \int_{x(0)}^{L} d F(x)-\Psi\right) U^{\prime}(w-P(\bar{x}(0))-(x-\bar{x}(0))) d F(x) \\
& >(1+\lambda) \int_{x(0)}^{L}\left((x-\bar{x}(0)) \int_{x(0)}^{L} d F(x)-\Psi\right) U^{\prime}\left(w-P(\bar{x}(0))-\frac{\Psi}{\int_{x(0)}^{L} d F(x)}\right) d F(x) \\
& =(1+\lambda) U^{\prime}\left(w-P(\bar{x}(0))-\frac{\Psi}{\int_{x(0)}^{L} d F(x)}\right) \int_{x(0)}^{L}\left((x-\bar{x}(0)) \int_{\bar{x}(0)}^{L} d F(x)-\Psi\right) d F(x) \\
& =0,
\end{aligned}
$$

which completes the proof. 


\section{Refarences}

Arrow, K., 1963, Uncertainty and the Welfare Economics of Medical Care, American Economic Review, 53: 941-973.

Besley, T., 1989, Publicly Provided Disaster Insurance for Health and the Control of Moral Hazard, Joumal of Public Eçonomics, 39: 141-156.

Crocker, K., and A. Snow, 1985, A Simple Tax Structure for Competitive Equilibrium and Redistribution in Insurance Markets with Asymmetric Information, Scandinavian Journal of Economics, 87: 1142-1150.

Doherty, N., 2000, Integrated Risk Management (New York: McGraw-Hill).

Doherty, N., and K. Smetters, 2005, Moral Hazard in Reinsurance Markets, Journal of Risk and Insurance, 72: 375-391.

Froot, K., D. Scharfstein, and J. Stein, 1993, Risk Management: Co-ordinating Investment and Financing Problems, Journal of Finance, 48: 1629-1658.

Garratt, R., and J. M. Marshall, 1996, Insurable Interest, Options to Convert, and Demand for Upper Limits in Optimum Property Insurance, Journal of Risk and Insurance, 63: 185-206.

Greenwald, B. C., and J. E. Stiglitz, 1990, Asymmetric Information and the New Theory of the Firm: Financial Constraints and Risk Behavior, American Economic Review, 80: 160-165.

Huberman, G., D. Mayers, and C. W. Smith, Jr., 1983, Optimal Insurance Policy Indemnity Schedules, The Bell Journal of Economics, 14: 415-426.

Kaplow, L., 1991a, Incentives and Government Relief for Risk, Journal of Risk and Uncertainty, 4: 167-175.

Kaplow, L., 1991b, The Income Tax as Insurance: The Casualty Loss and Medical Expense Deductions and the Exclusion of Medical Insurance Premiums, California Law Review, 79: 1485-1510.

Kaplow, L., 1992a, Government Relief for Risk Associated with Government Action, Scandinavian Journal of Economics, 94: 525-541.

Kaplow, L., 1992b, Income Tax Deductions for Losses as Insurance, American Economic Review, 82: 1013-1017.

Mossin, J., 1968, Aspects of Rational Insurance Purchasing, Journal of Political Economy, 4: 553-568.

Petretto, A., 1999, Optimal Social Health Insurance with Supplementary Private Insurance, Journal of Health Economics, 18: 727-745.

Picard, P., 2000, On the Design of Optimal Insurance Policies under Manipulation of Audit Cost, International Economic Review, 41: 1049-1071.

Raviv, A., 1979, The Design of an Optimal Insurance Policy, American Economic Review, 69: 84-96.

Rejda, G. E., 1998, Principles of Risk Management and Insurance (Boston, MA: AddisonWesley).

Selden, T. M., 1993, Should the Government Provide Catastrophic Insurance? Journal of Public Economics, 51: 241-247. 
Selden, T. M., 1999, Premium Subsidies for Health Insurance: Excessive Coverage vs. Adverse Selection, Journal of Health Economics, 18: 709-725.

Smith, C. W., Jr., and R. Stulz, 1985, The Determinants of Firms' Hedging Policies, Journal of Financial and Quantitative Analysis, 20: 391-405.

Stiglitz, J. E., 1989, Mutual Funds, Capital Structure, and Economic Efficiency, in: S. Bhattacharya and G. Constantinides, eds., Theory of Valuation-Frontiers of Modern Financial Theory (Totowa, NJ: Rowman and Littlefield), pp. 342-356.

Stiglitz, J. E., 2002, Information and the Change in the Paradigm in Economics, American Economic Review, 92: 460-501.

Tufano, P., 1996, Who Manages Risk? An Empirical Examination of Risk Management Practices in the Gold Mining Industry, Journal of Finance, 51: 1097-1137. 